\title{
Modern cardiopulmonary resuscitation-not so new after all
}

Raymond Hurt FRCS DHMSA

J R Soc Med 2005;98:327-331

'Death may usurp on nature many hours, And yet the fire of life kindle again

The o'pressed spirits. I heard of an Egyptian

That had nine hours lien dead,

Who was by good appliances recover'd.'-Shakespeare, Pericles, Act 3, Scene 2

'The suspension will more frequently last forever, unless the power of life is restored to action by some application of art.'-John Hunter Phil Trans $1776 ; 66: 413$

It was in 1960 that Kouwenhoven published his landmark paper on cardiopulmonary resuscitation (CPR) and in his own words 'anyone, anywhere can initiate cardiac resuscitation procedures. All that is needed are two hands'. ${ }^{1}$ Expired air respiration (the 'kiss of life') had been reintroduced two years previously.

These two techniques had both been known to the medical profession in the eighteenth and nineteenth centuries but had been abandoned as being unsatisfactory until their revival in the mid-twentieth century. The whole history of CPR is remarkable for the introduction of new techniques subsequently to be replaced by those thought previously to have been unsatisfactory.

\section{STERNAL COMPRESSION, 1868}

The following description of sternal compression was written by John Hill of the Royal Free Hospital in 1868. But it could equally be a present-day description of external cardiac massage.

'The surgeon's left hand was placed firmly across the front of the chest, the fingers resting over the fifth, sixth and seventh costal cartilages on the right side, while the tip of the thumb lay on the second piece of the sternum and the muscular part of the hand on the corresponding cartilages on the left side. The right hand was now crossed over the left and forcible pressure made; the hands then being suddenly removed, the chest was allowed to expand by its own elasticity'.2

The White House, 8 Loom Lane, Radlett, Herts WD7 8AD, UK

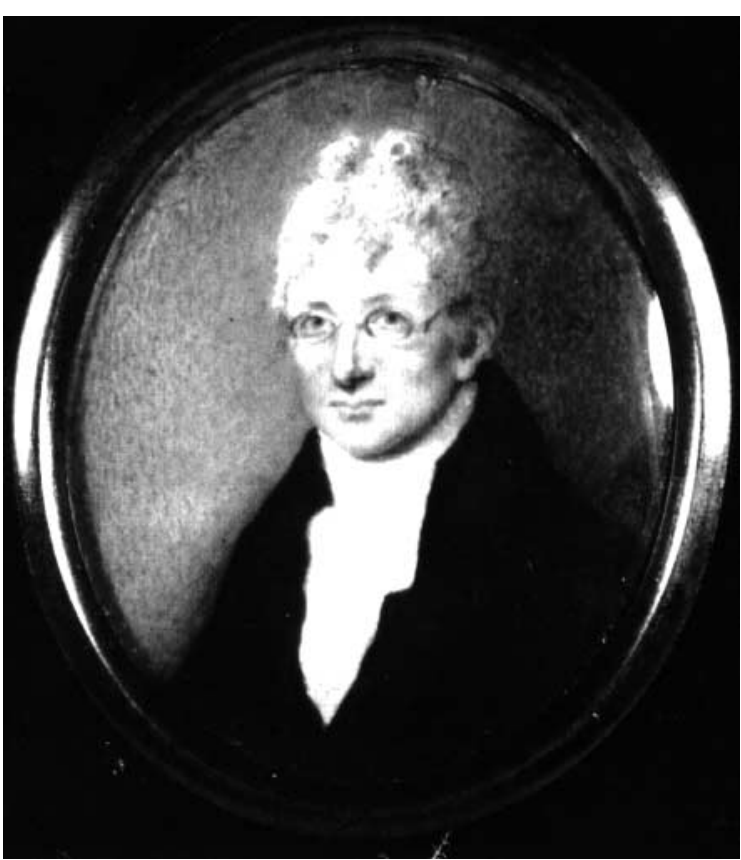

Figure 1 James Curry (d. 1819) (Courtesy of the Royal College of Physicians, London)

Hill described the restoration of heartbeat in three patients who were apparently dead, with no carotid pulse and no audible heart sounds. The pressure on the chest was applied twelve times a minute. Was it to compress the heart or was it a method for artificial respiration? Probably the latter, for the patient's recovery was attributed mainly to the inhalation of ammonia from a large sponge placed across the nostrils. The article concluded that the 'process is simple in the extreme, requiring little or no assistance, not even the movement of the patient from his position and thus attended by no labour to the operator'. Except for the rate of chest compression the technique was almost identical to that described by Kouwenhoven in 1960, almost one hundred years later, though for a different reason.

\section{DISTINCTION BETWEEN APPARENT AND ABSOLUTE DEATH}

James Curry (d. 1819) (Figure 1), a Northampton physician who was later elected to the staff of Guy's Hospital, 


\section{POPULAR OBSERVATIONS}

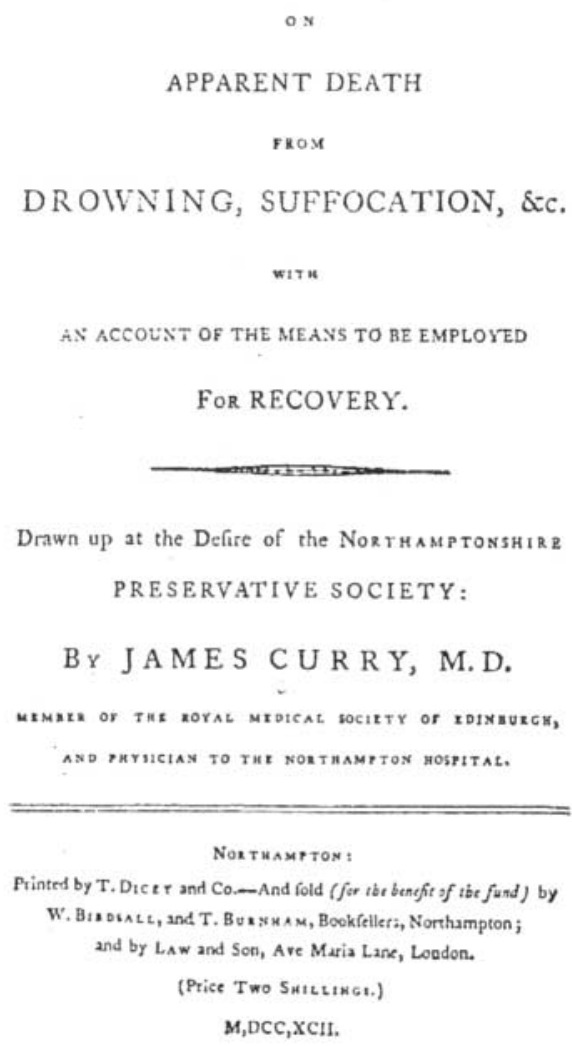

Figure 2 Title page of James Curry's Popular Observations on Apparent Death from Drowning, Suffocation etc (1792)

London, made the first attempt to place resuscitation on a scientific basis in 1792 when he published Popular Observations on Apparent Death from Drowning, Suffocation etc (Figure 2), of which 500 copies were printed. ${ }^{3}$ As a result of his animal experiments and clinical observations he was able to distinguish between recoverable apparent death ('which only lies dormant') and the later development of absolute death ('in which the vital principle is completely extinguished'). He described three patients with temporary recovery after apparent death.

\section{EARLY METHODS FOR ARTIFICIAL VENTILATION}

\section{Expired-air respiration}

Expired-air respiration is clearly described in the Bible. It was probably carried out by Elijah and certainly by Elisha. ${ }^{4}$ peasant midwives.
The first detailed case history of resuscitation by this technique was reported to the Edinburgh Medical Society in 1744 by Tossach, who had successfully revived a coal miner overcome by poisonous gases. ${ }^{5} \mathrm{He}$ described the technique as 'very simple and absolutely safe and can at least do no harm'. The implications of this report were not much appreciated in the UK but in Holland it attracted considerable attention, leading to the establishment of the first Humane Society for the resuscitation of the apparently drowned. Many such cases occurred in the Dutch canals, especially in icy winters. This new society advocated expired-air respiration, as did all the humane societies subsequently established all over Europe and on the east coast of the United States. The expiratory phase of respiration was encouraged by pressure on the chest and abdomen by the free hand. The instructions provided by the English Humane Society in its first annual report in 1775 included:

'Artificial respiration [was] carried out in the following manner. The operator closed the patient's nostrils and applied his mouth to his and thus inflated the lungs and expanded the belly and the chest. By compressing these parts with his free hand the operator brought about an expiratory movement' ${ }^{6}$

\section{Mechanical ventilation}

Mechanical ventilation by bellows introduced into the trachea was used by Vesalius in the sixteenth century, and two centuries later John Hunter was able to restart the heart after anoxic arrest if artificial ventilation through a tracheostomy was begun within ten minutes.

By the late eighteenth century ventilation by bellows was considered preferable to expired-air respiration and was adopted by all the humane societies from 1782 onwards. 'Resuscitation sets' were placed at selected sites along the Thames for immediate use in cases of drowning. Inflation of the stomach was prevented by external compression of the oesophagus in the neck, as had originally been advised by Hunter (and was later to become known as the Sellick manoeuvre for the prevention of oesophageal reflux during induction of anaesthesia). Endotracheal intubation was introduced by Charles Kite in 1788- for which he was awarded a silver medal by the Royal Humane Society (Figure 3). ${ }^{7}$

By the early nineteenth century, however, both expiredair ventilation and mechanical ventilation were abandoned by the humane societies in favour of external chest compression, partly because it was considered unwise to ventilate the lungs with air that had already had some of its oxygen removed and partly because of the risk of lung 
rupture. The bellows was judged a 'lethal weapon which should be relegated to its former place by the fireside'. ${ }^{8}$

Techniques for external compression of the chest were described by Marshall Hall, Sylvester, and others, all of which were analysed in great detail by Sir Arthur Keith in three masterly Hunterian lectures in $1909 .{ }^{6}$ However, Safar (Baltimore) showed in 1958 that it was only by expired-air respiration that adequate ventilation was obtained, and furthermore that hyperventilation by the operator made his expired air almost like room air. ${ }^{9}$ Keith had taken this view in 1909, though without scientific proof.

\section{CARDIAC COMPRESSION (MASSAGE)}

The possibility of resuscitating an arrested heart was described in 1628 by William Harvey, who had observed restoration of the heartbeat in doves:

'Trying an experiment on a dove, after the heart had quite left motion and that the ears [atrial appendages] had quite given over, I wettd my finger with spittle and being

$\wedge \mathrm{N}$

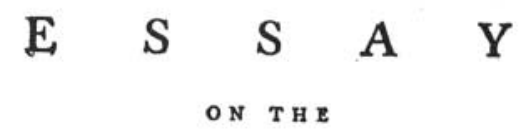

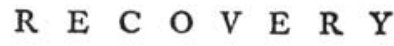

OF THE

\section{A P PARENTL Y DEAD.}

BY CHARLES KITE,

Member of the Corporation of Surgeons in London, and Surgeon at Gravefend in Kent.

Being tbe Effay to wbicb tbe Humane Society's Medal was adjudged.

To which is prefixed,

D R. LETTSOM's A D D E S S

ON THE DELIVERY OF THE MEDAL.

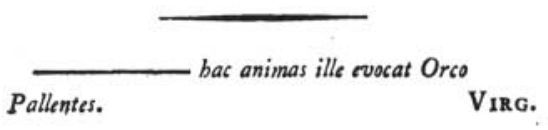

L O N D O N :

PRINTED FOR C. DILLY IN THE POULTRY.

M,DCC.LXXXVIII.

Figure 3 Title page of Charles Kite's Essay on the Recovery of the

Apparently Dead (1788) (Courtesy of the British Library)

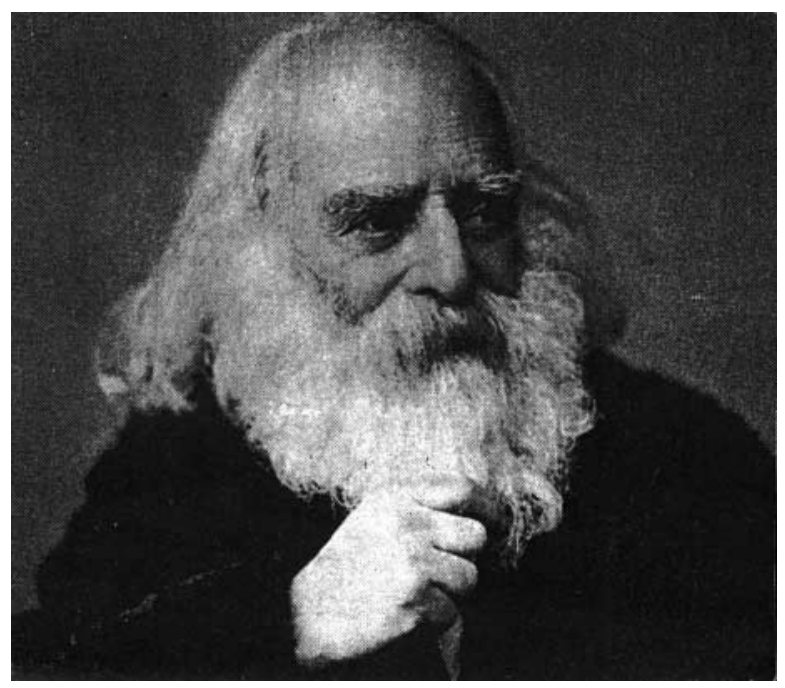

Figure 4 Moritz Schiff (1823-96); the founder of internal cardiac massage. (Reproduced by permission from Milstein BB, Cardiac Arrest and Resuscitation, Lloyd-Luke, 1963)

warmed kept it awhile on the heart; the heart and its ears began to contract and did seem as if it were recalled back again from death'. ${ }^{10}$

\section{Moritz Schiff, the founder of internal cardiac massage}

Moritz Schiff (1823-1896), professor of physiology in Florence (Figure 4), made fundamental observations on the cause and treatment of cardiac arrest in 1874 while studying the cause of death under chloroform and ether anaesthesia in animals. ${ }^{11}$ Noting that cardiac arrest preceded respiratory arrest he considered that treatment by chest compression, ventilation or the application of electricity was of no use. But 'if one opens the thorax whilst air is slowly blown into the lungs and compresses the heart rhythmically with the hand to squeeze out the blood, compressing the abdominal aorta at the same time so that more of the artificial circulation is directed to the head, one can restore the heart as long as eleven and a half minutes after it has been arrested'. He thus stressed the fundamental principle that the renewed activity of the heart was not merely the result of its mechanical irritation but also depended on an increased supply of oxygenated blood to the myocardium through the restored coronary circulation.

\section{Successful cardiac resuscitation in man}

Attempts to restore cardiac activity in man by internal massage were made in the late nineteenth century and success was first obtained by Igelsrud (Tromsø, Norway) in 1901 (reported by Keen). After a cardiac arrest towards the end of an abdominal operation the heart was exposed by resection of parts of the fourth and fifth ribs, the pericardium was opened and the heart was massaged 
'between the thumb on one side and the fore and middle fingers on the other'. Pulsation returned after one minute and the patient made a complete recovery. ${ }^{12}$

A second case was reported in 1902. During an appendicectomy by Arbuthnot Lane (London) under ether anaesthesia, cardiac and respiratory arrest had occurred simultaneously. Artificial respiration was performed and the heart started again 'after a squeeze or two' from below the diaphragm. ${ }^{13}$

By 1909 forty-eight cases had been reported and success had been achieved in ten. Massage had been performed through the open chest or the abdomen, either through an incision in the diaphragm in the midline to open the pericardium or through the intact diaphragm from below. ${ }^{14}$ By 1952 a success rate of almost one-third was achieved. ${ }^{15}$

\section{External cardiac compression}

The possibility that external compression of the heart without opening the chest would provide an adequate circulation was first shown in cats by Boehm (Dorpat, Germany) in 1878: 'It can easily be seen that for a long time one could keep up a kind of emergency circulation; as soon as the compression is decreased the heart refills itself from the main veins, so that again and again fresh blood will be forced out of the heart'. ${ }^{16}$ This work was confirmed in dogs by George Crile in Cleveland, USA, and its use in seven human cases was reported in 1904, 'one successfully and two partially so'. ${ }^{17}$ However, following the work of Schiff in 1896, external cardiac compression was abandoned in the early twentieth century in favour of internal massage through an open chest and this continued to be used until the work of Kouwenhoven half a century later.

\section{William Kouwenhoven}

William Kouwenhoven (1886-1975) (Figure 5) rediscovered external cardiac compression by accident during his research on internal and external defibrillation, and so became the founder of modern CPR. Born in New York he obtained a doctorate in electrical engineering in Germany. In 1914 he joined the staff of Johns Hopkins University, Baltimore, and in 1928 began to study the effect of electric current on the heart. By 1933 his team had developed satisfactory systems for both internal and external defibrillation. ${ }^{1}$ The greatest advance in the treatment of cardiac arrest since the time of Schiff was made when he demonstrated on a dog's fibrillating heart that an adequate circulation could be maintained for up to thirty minutes by external compression of the chest wall. This work culminated in 1960 when he reported a 70\% survival rate in twenty patients and emphasized that it was possible to treat a cardiac arrest outside a hospital environment and

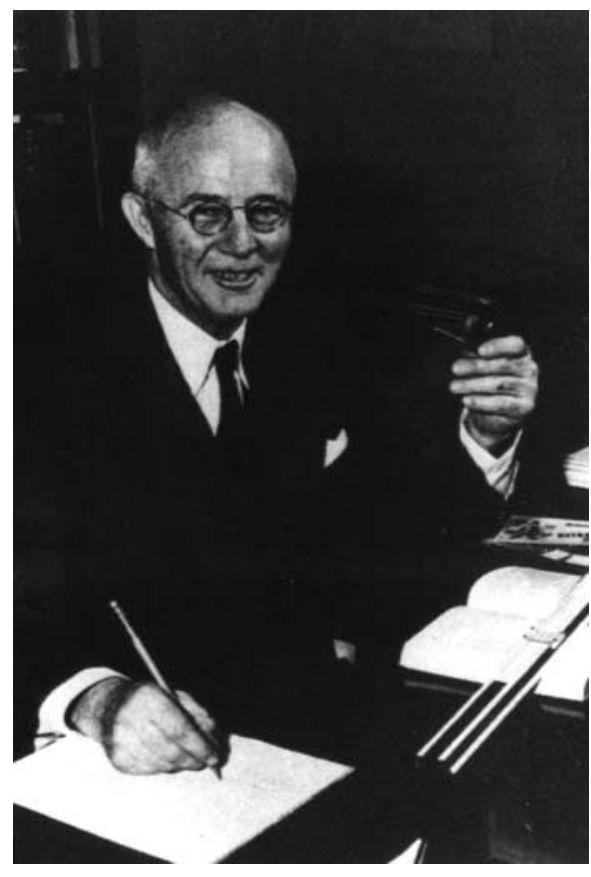

Figure 5 William Kouwenhoven (1886-1975) (Reproduced by permission from Bolling SF Ann Thorac Surg 1990;49:155)

time of this publication he was aged 74 years and still working at Johns Hopkins University.

Kouwenhoven's chance discovery of external cardiac compression was made while investigating the technique of defibrillation of the heart. Heavy paddles had been placed on the chest of a dog in cardiac arrest and it was noticed that the weight of these heavy paddles increased the animal's blood pressure. It was then discovered that an adequate circulation to the brain could be maintained by rhythmic pressure on the animal's sternum- $36 \mathrm{~kg}$ of pressure every second. Relaxation of this pressure allowed the heart again to fill. This effect of compression of the heart between the sternum and the spine was confirmed in over a hundred dogs. It also emerged that a heart which had been in ventricular fibrillation for up to thirty minutes could be restored to sinus rhythm if external cardiac compression had been maintained during this time.

\section{DEFIBRILLATION OF THE HEART}

The introduction of defibrillation of the heart followed a more conventional pattern. It was first studied experimentally in 1899 by Prévost and Batelli (Geneva), who showed that electrically induced fibrillation could be reversed by a 240 volt alternating-current shock if applied to the heart within fifteen seconds. They also made the fundamental observation that, if a longer period elapsed, cardiac massage was necessary to provide myocardial oxygenation. ${ }^{18}$ Successful internal and external defibrillation in man was not achieved until half a century later. 


\section{Internal defibrillation}

Internal defibrillation was used successfully in 1947 by Beck (Cleveland) during an operation for correction of a funnel chest deformity. In this dramatic case cardiac massage had been performed for thirty-five minutes, during ten of which the heart had been in ventricular fibrillation. ${ }^{19}$

In 1954 Brock (London) reported a series of thirty patients in whom ventricular fibrillation had developed during the course of a cardiac operation. Defibrillation was performed in twenty and nine of these recovered. The importance of preliminary cardiac massage was again emphasized (as recommended by Schiff 80 years earlier). ${ }^{20}$

The first successful internal defibrillation on a patient not undergoing an operation was performed by Reagan (New Jersey) in 1953 on a patient who had developed ventricular fibrillation while an electrocardiogram was being taken after an acute coronary occlusion. ${ }^{21}$ The chest was opened without sterile precautions and defibrillation was performed after a preliminary period of cardiac massage. A second successful defibrillation was reported by Beck in 1956 on a physician who collapsed while unwisely leaving hospital after electrocardiography had shown an early posterolateral infarct. ${ }^{22}$ Ventricular fibrillation was confirmed when the chest was opened in the nearby emergency operating room and the 'heart squeezed intermittently against the sternum'. There was no response to two shocks so the pericardium was opened and defibrillation was obtained after three further shocks.

\section{External defibrillation}

External defibrillation had first been suggested by Curry, an advisor to the Royal Humane Society, following his experimental work on small animals and in 1792 he recorded two successful cases of human resuscitation by this means. He used two electrodes, one above the clavicle and the other over the lower left chest. ${ }^{3}$ Two years later a further case was reported in the Transactions of the Royal Humane Society. 23,24 A young child had fallen out of a window and was 'to all appearances dead' when taken to hospital. Electric shocks from a friction type electrostatic electricity machine 'transmitted through the thorax' successfully re-established the circulation and 'her health was restored'.

Finally, Kouwenhoven's work described above established the modern technique for CPR.

Note Those seeking more information on this subject should consult the chapter on CPR in The History of Cardiothoracic Surgery by R Hurt (Carnforth: Parthenon 1996) which contains much more historical detail, 73 references and 15 illustrations. In addition, the story of resuscitation medicine and why modern CPR was delayed for so long was discussed comprehensively by Chamberlain in $2003 .{ }^{25}$

\section{REFERENCES}

1 Kouwenhoven WB, Jude JR, Knickerbocker GG. Closed chest cardiac massage. JAMA 1960;173:1064-7

2 Hill JD. Observations on some of the dangers of chloroform in surgical practice, and a successful mode of treatment. Br J Dent Sci 1868;11:355-8

3 Curry J. Popular Observations on Apparent Death from Drowning, Suffocation etc. London: Law, 1792

4 Bible. I Kings 17, v. 21, II Kings, 4 v. 34

5 Dagi F. Exhortations to resuscitate in the 18th century. In: Atkinson RS, Boulton TB, eds The History of Anaesthesia. London: RSM Press, 1989:359-67

6 Keith A. The mechanism underlying the various methods of artificial respiration. Lancet 1909;1;745-9, 825-8, 895-9

7 Kite C. An Essay on the Recovery of the Apparently Dead. London: Dilly, 1788

8 Leroy M. Magendie's Journal de Physiologie 1829;9:187. Reported in the Annual Report of the Royal Humane Society. London: 1832 and also cited by Keith, ref. 6

9 Safar P, Escaragga LA, Elam JO. A comparison of mouth-to-mouth and mouth-to-airway methods of artificial respiration with the chestpressure arm-lift methods. N Engl J Med 1958;258:671-7

10 Harvey W. De Mortu Cordis (1628), edited by Geoffrey Keynes. USA: Lustar Press, 1978

11 Schiff M. Recueil des Mémoires Physiologique, Vol. 3. Cited by Milstein BB, Cardiac Arrest and Resuscitation. London: Lloyd Luke, 1963

12 Keen WW. A case of total laryngectomy (unsuccessful) and a case of abdominal hysterectomy (successful) in both of which massage of the heart for chloroform collapse was employed, with notes of 25 other cases of cardiac massage. Ther Gaz 1904;28:217-30

13 Starling EA, Lane WA. Report of Society of Anaesthetists. Lancet 1902;2:1397

14 White CS. Role of heart massage in surgery. Surg Gynecol Obstet 1909;9:388-400

15 Bost TC. Cardiac arrest during anaesthesia and surgical operations. Am J Surg 1952;83:135-42

16 Boehm R. Ueber wiederbelebung nach vergiftungen und asphyxie. Arch Exp Pathol Pharmakol 1878;8:68-101

17 Crile GW. Blood Pressure in Surgery. Philadelphia: Lippincott, 1903:294

18 Prévost JL, Batelli F. Quelques effets des décharges électrique sur le coeur des mammifères. J Physiol Path Gén 1900;2:40-52

19 Beck CS, Pitchard WH, Feil HS. Ventricular fibrillation of long duration abolished by electric shock. JAMA 1947;135:985-6

20 Milstein BB, Brock RC. Ventricular fibrillation during cardiac surgery. Guy's Hosp Rep 1954;103:213-59

21 Reagan LR, Young KR, Nicholson JW. Ventricular defibrillation in a patient with probable acute coronary occlusion. Surgery 1956;39: 482-6

22 Beck CS, Weckesser EC, Barry FM. Fatal heart attack and successful defibrillation. JAMA 1956;161:434-6

23 Royal Humane Society. Transactions. London: Royal Humane Society, 1797-98:51

24 Perman E. Successful cardiac resuscitation with electricity in the 18 th century? BMJ 1978;2:1770-1

25 Chamberlain D. Never quite there: a tale of resuscitation medicine. Clin Med 2003;3:573-7 